\title{
Emphysema Findings Associated with Heavy Asbestos-Exposure in High Resolution Computed Tomography of Finnish Construction Workers
}

\author{
Olli Huuskonen ${ }^{1}$, Leena KivisaAri ${ }^{2}$, Anders Zitting $^{1}$, Simo Kaleva ${ }^{1}$ and Tapio Vehmas ${ }^{1}$ \\ ${ }^{1}$ Finnish Institute of Occupational Health and ${ }^{2}$ Helsinki University Central Hospital, Department of Radiology, \\ Finland
}

\begin{abstract}
Emphysema Findings Associated with Heavy Asbestos-Exposure in High Resolution Computed Tomography of Finnish Construction Workers: Olli HuUsKonen, et al. Finnish Institute of Occupational Health, Helsinki, Finland-Asbestos fibers are known to cause lung fibrosis, but their role in emphysema is unclear. We wanted to evaluate the relationship between asbestos exposure and emphysema by using high-resolution computed tomography (HRCT). Conventional and high resolution CT was performed on 600 smoking construction workers with an asbestos-related occupational disease. Emphysema subtypes (centrilobular, paraseptal, panlobular emphysema and bullae) were separately scored on a semiquantitative scale from 0 to 5 , which scores were added up to yield the total emphysema score. Occupation, exposure duration, age, pack years and asbestosis diagnosis were analyzed in general linear models for possible associations with emphysema. The inter- (quadratic weighted kappa, $\left.\kappa_{\mathrm{qw}}=0.46-0.72\right)$ and intraobserver $\left(\kappa_{\mathrm{qw}}=0.78-0.94\right)$ agreements for the subtype-scores and the reliability of the total score (Cronbach's alpha=0.87) were good. Insulators had a significantly higher paraseptal, panlobular and total score than the other occupational groups when adjusted for age and smoking. An asbestosis diagnosis was also a significant independent predictor of a higher total score. Emphysema was more common when workers had asbestosis or were heavily exposed to asbestos (insulators), but due to confounding factors the causative role of asbestos in emphysema needs further study.

(J Occup Health 2004; 46: 266-271)
\end{abstract}

Received Nov 20, 2003; Accepted May 14, 2004

Correspondence to: T. Vehmas, Finnish Institute of Occupational Health, Radiology Unit, Topeliuksenkatu 41 a A, FIN-00250 Helsinki, Finland

(e-mail:tapio.vehmas@occuphealth.fi)
Key words: Asbestosis, Lung diseases, Obstructive, Occupational diseases, Occupational groups, Tomography, X-ray computed

Construction workers are exposed to a variety of inhaled agents that have adverse effects on the lungs, e.g. mixed dusts containing silica, asbestos, quartz, manmade fibers and various other building materials. It has been established that occupational exposure to silica causes pulmonary emphysema in addition to silicosis ${ }^{1,2)}$. Emphysema has also been associated with coal worker's pneumoconiosis ${ }^{3)}$. The main nonmalignant diseases caused by asbestos exposure are pleural disorders and interstitial lung fibrosis, leading eventually to asbestosis ${ }^{4)}$.

High resolution computed tomography has proven to be more sensitive and reliable than chest radiography especially in the early stages of emphysema ${ }^{5-7}$. The disease is visible as hypodense areas in the lung parenchyme. Subtypes of emphysema can be differentiated based on their appearance in HRCT. Centrilobular emphysema is characterized by numerous small lucencies predominantly in the upper lobes, whereas in paraseptal emphysema the lucencies are found in subpleural areas. Panlobular emphysema causes an overall decrease in lung attenuation without focal lucencies. Emphysematous bullae are seen as large, sharply demarcated lucencies measuring at least $1 \mathrm{~cm}$ in diameter ${ }^{8)}$. Of these subtypes centrilobular emphysema is usually associated with cigarette smoking ${ }^{9}$.

This study is part of a national asbestos program, aiming to minimize all exposure to asbestos, to identify people exposed occupationally and to improve the diagnostics of asbestos-related diseases. We wanted to work out the possible association of occupation and asbestos exposure with HRCT findings of emphysema in construction workers while adjusting for age and smoking habit. 


\section{Materials and Methods}

Study subjects

The study subjects were identified in a previous study among 18,900 Finnish persons exposed to asbestos ${ }^{10)}$. Out of the 2,857 persons with an asbestos-related occupational disease, those (600; 589 men and 11 women) living in the Helsinki area, willing to participate, and with sufficient data available formed the study group. Inclusion criteria were asbestosis with or without smoking ( $n=122$, out of which 85 cases had been diagnosed at the start of the primary study) or bilateral pleural plaques without asbestosis and a history of smoking for at least 10 years $(n=488)$. The mean age of the group was 64 (ranging from 38 to 81 ) yr. Most subjects had been occupationally exposed to asbestos-containing materials for over 20 (mean 26) yr and had smoked 24 packs a year on average. Twenty subjects with asbestosis were lifetime non-smokers.

All subjects were examined and interviewed personally by an occupational physician. The interview was structured and included questions on the subjects' smoking habits and occupational history. Experts in the assessment of asbestos exposure (an occupational physician and an occupational hygienist) evaluated the patients' occupational histories and the subjects were classified based on their main occupation (Table 1). The groups were numbered according to the estimated increasing asbestos-exposure (groups 1-5) based on an asbestos screening study among Finnish construction workers ${ }^{10,11)}$. The group "Insulators", who had worked as asbestos sprayers and also at dismantling asbestoscontaining insulations, were estimated to have the heaviest exposure. The subjects in the group "Others" represented various occupational groups with heterogeneous asbestos-exposure. Their predominant occupational title was "construction site cleaner".

The study group included 121 patients with asbestosis. The diagnoses were based on the patient's symptoms, occupational history (sufficient exposure according to the clinical experience at the Finnish Institute of Occupational Health), a typical pattern in lung function tests (restriction and impaired diffusion capacity) and a suggestive finding of fibrosis in HRCT, and that other possible diseases were excluded.

\section{Imaging}

Unenhanced spiral CT was performed for all exposed workers with a Picker PQ 2000 scanner (Picker International, USA) in the supine position and at full inspiration from the apices to the costophrenic angle (125 $\mathrm{mA}, 140 \mathrm{kV}$, collimation $10 \mathrm{~mm}$, pitch 1.5). The images were reconstructed with a $10-\mathrm{mm}$ slice thickness and a standard algorithm and printed at two settings: window width (WW) 1,000 Hounsfield units (HU) and window level (WL) -700 HU for viewing the lung parenchyme and WW $400 \mathrm{HU}$, WL $40 \mathrm{HU}$ for the mediastinum and pleura. In addition, 4-7 HRCT slices were scanned from the aortic arch or pulmonary hila to the lung bases (200 $\mathrm{mA}, 130 \mathrm{kV}$, slice thickness 1,5 mm, WW 1,000 HU, WL $-700 \mathrm{HU})$. All imaging was performed with the patient's informed consent and permission from the local ethical committee.

\section{Image analysis}

All images were reviewed by 3 experienced radiologists (LK, TV and AZ) separately, blinded from all clinical data, except from the patient's name and date of birth which were printed on the images. A structured form was filled out at each reading considering pulmonary emphysema (centrilobular, paraseptal and panlobular emphysema and bullae). The findings were scored on an arbitrary scale from 0 to 5 , where 0 means no sign of emphysema, 1 stands for slight and 5 for extreme ehphysematous changes.

Fibrosis was also scored on an arbitrary scale from 0 to 5. The score was based on the signs of fibrosis in HRCT, such as subpleural curvilinear opacities, subpleural perpendicular lines, parenchymal bands and honeycombing. This scale was reported in detail in an earlier work by the authors ${ }^{12}$.

A set of 43 (HR)CT examinations was double-read by each observer to estimate intraobserver agreement. The interval between the readings was at least one month.

Table 1. Characteristics of the patients enrolled in the study

\begin{tabular}{lrrrrrrr}
\hline \multirow{2}{*}{ Occupational group } & \multirow{2}{*}{$\mathrm{N}$} & \multicolumn{2}{c}{ Age (years) } & \multicolumn{2}{c}{ Smoking (pack years) } & \multicolumn{2}{c}{ Exposure duration (years) } \\
\cline { 3 - 7 } & & mean & SD & mean & SD & mean & SD \\
\hline 1. Engineers & 41 & 65.3 & 6.7 & 23.7 & 15.5 & 29.9 & 9.7 \\
2. Electricians & 52 & 57.9 & 6.2 & 20.3 & 13.4 & 24.3 & 9.3 \\
3. Carpenters & 129 & 64.9 & 7.3 & 23.9 & 14.3 & 28.1 & 8.6 \\
4. Plumbers & 74 & 60.2 & 7.4 & 23.1 & 14.6 & 26.7 & 10.8 \\
5. Insulators & 36 & 60.5 & 7.3 & 23.4 & 17.2 & 17.8 & 9.5 \\
6. Others & 268 & 63.0 & 7.1 & 24.4 & 15.5 & 25.3 & 9.4 \\
\hline
\end{tabular}




\section{Statistical analysis}

The pooled observer agreement considering the abovementioned emphysematous findings was evaluated by quadratic weighted kappa $\left(\kappa_{\mathrm{qw}}\right)$, which is equal to intraclass correlation ${ }^{13)}$. CT findings with a $\kappa_{\mathrm{qw}}>0.4$ were considered reliable and were used in further analyses. After the $\kappa_{\mathrm{qw}}$-values were computed, the radiologists' mean scores on both sides were used in further computations.

A total variable, the emphysema total score (ranging from 0 to 20), was calculated by adding together individual scores considering emphysema variables. Cronbach's alpha $(\alpha)^{13)}$ was used to study the reliability of the method, i.e. how well the recorded different radiological findings of emphysema reflect the same disease. The closer the $\alpha$-value is to 1 the better the reliability is. A value of at least 0.7 was considered good.

General linear models were used to study the relationships between the independent variables (occupational group, age, pack years, the duration of exposure and the asbestosis diagnosis) and the dependent variables (HRCT emphysema total score and the individual emphysema subtype scores). The analysis begins with a preliminary model including all the independent variables. The insignificant variables are removed from the model through backward elimination, aiming at the least possible number of significant variables. The qualitative variables (occupational group and asbestosis diagnosis) in the models were compared to a chosen reference group (0-level) which other groups were compared to (insulators and patients without asbestosis, respectively). The analysis yields an estimate of the change in the dependent variable resulting from a change of one unit in the independent variable, and a coefficient of determination $\left(\mathrm{r}^{2}\right)$, which corresponds to the proportion of the variance in the dependent variable that is explained by the model.

All analyses were performed with SPSS statistical software (Version 10.1, SPSS Inc. Chicago, IL, USA).

\section{Results}

The method

The quadratic weighted kappa $\left(\kappa_{\mathrm{qw}}\right)$-values describing agreement are shown in Table 2. Intraobserver agreement

Table 2. Observer agreement

\begin{tabular}{lcc}
\hline Emphysema type & Inter-observer & Intra-observer \\
\hline Centrilobular & $0.72(0.69-0.74)$ & $0.83(0.78-0.97)$ \\
Paraseptal & $0.68(0.65-0.71)$ & $0.94(0.92-0.95)$ \\
Panlobular & $0.46(0.42-0.50)$ & $0.78(0.72-0.82)$ \\
Bullae & $0.60(0.57-0.64)$ & $0.92(0.89-0.94)$ \\
\hline
\end{tabular}

Quadratic weighted kappa, 95\% confidence intervals in parentheses

Table 3. Distribution of the emphysema subtype-scores*) in occupational groups

\begin{tabular}{|c|c|c|c|c|c|c|c|c|}
\hline & & \multicolumn{7}{|c|}{ Occupational group } \\
\hline & & Engineers & Electricians & Carpenters & Plumbers & Insulators & Others & Total \\
\hline \multicolumn{9}{|c|}{ Emphysema type } \\
\hline \multicolumn{2}{|c|}{ Centrilobular } & $\%$ & $\%$ & $\%$ & $\%$ & $\%$ & $\%$ & $\%$ \\
\hline 0 & $(<0.5)$ & 75 & 88 & 81 & 85 & 72 & 80 & 81 \\
\hline 1 & $(<1.5)$ & 15 & 10 & 9 & 8 & 8 & 11 & 10 \\
\hline 2 & $(<2.5)$ & 10 & 2 & 6 & 4 & 8 & 7 & 6 \\
\hline $3-5$ & $(\geq 2.5)$ & 0 & 0 & 3 & 3 & 11 & 3 & 3 \\
\hline \multicolumn{9}{|c|}{ Paraseptal } \\
\hline 0 & $(<0.5)$ & 85 & 94 & 89 & 92 & 75 & 88 & 88 \\
\hline 1 & $(<1.5)$ & 15 & 6 & 5 & 5 & 6 & 7 & 7 \\
\hline 2 & $(<2.5)$ & 0 & 0 & 4 & 3 & 11 & 3 & 3 \\
\hline $3-5$ & $(\geq 2.5)$ & 0 & 0 & 2 & 0 & 8 & 2 & 2 \\
\hline \multicolumn{9}{|c|}{ Panlobular } \\
\hline 0 & $(<0.5)$ & 78 & 94 & 87 & 88 & 72 & 80 & 83 \\
\hline 1 & $(<1.5)$ & 20 & 4 & 10 & 11 & 14 & 15 & 13 \\
\hline 2 & $(<2.5)$ & 0 & 2 & 2 & 0 & 8 & 2 & 2 \\
\hline 3-5 & $(\geq 2.5)$ & 3 & 0 & 2 & 1 & 6 & 2 & 2 \\
\hline \multicolumn{9}{|c|}{ Bullae } \\
\hline 0 & $(<0.5)$ & 88 & 94 & 91 & 95 & 69 & 91 & 90 \\
\hline 1 & $(<1.5)$ & 12 & 4 & 5 & 5 & 25 & 7 & 7 \\
\hline 2 & $(<2.5)$ & 0 & 2 & 2 & 0 & 6 & 0 & 1 \\
\hline $3-5$ & $(\geq 2.5)$ & 0 & 0 & 2 & 0 & 0 & 2 & 1 \\
\hline
\end{tabular}

The scores are averages for 3 readers: 0 meaning $<0.5,1$ meaning $\geq 0.5$ and $<1.5$, etc. 
was higher than interobserver agreement in all variables. All $\kappa_{\mathrm{qw}}$-values were over 0.4 and significantly different from 0 .

The reliability of the emphysema total score as a method was considered good $(\alpha=0.87)$. Deleting

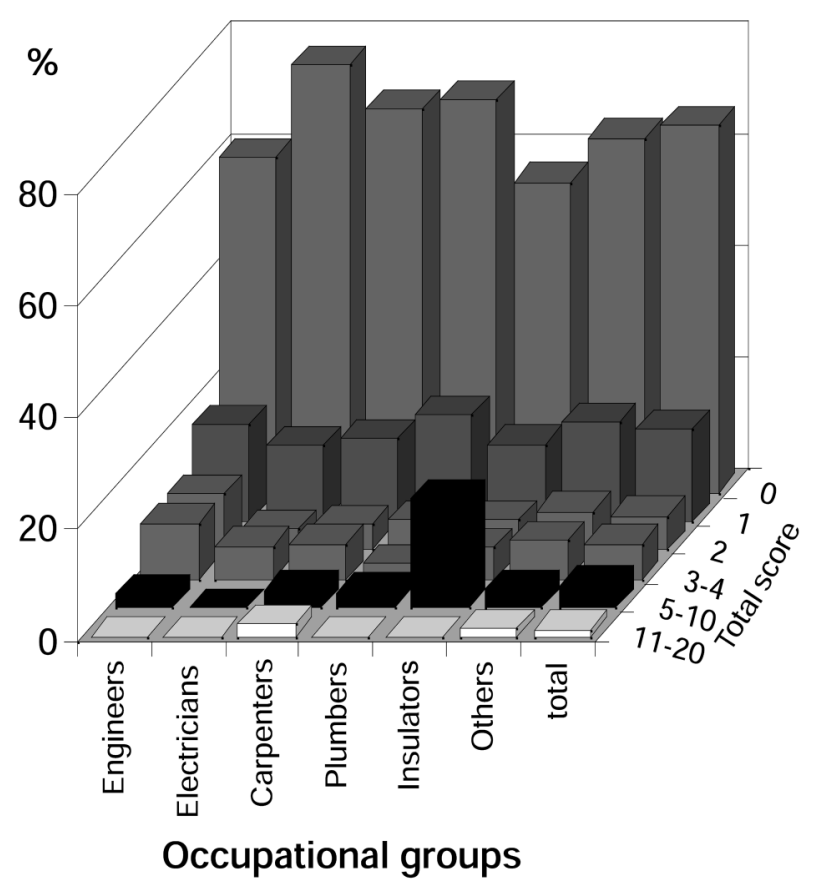

Fig. 1. Distribution of the HRCT emphysema total score in the occupational groups. individual emphysema types from the total score did not improve reliability.

\section{Findings}

Most of the exposed workers had no sign of emphysema visible in HRCT. The percentage of no emphysema signs (i.e. two out of 3 radiologists had scored the variable as 0 , average score $<0.5$ ) ranged from 80 to 90 on average in the different subtypes of emphysema. The emphysema findings grouped by occupation are shown in Table 3. Regarding the total score, mild emphysema $(0.5 \leq$ total score $<4.5)$ was present in $29 \%$ of subjects in HRCT. Five percent had a more severe disease (Fig. 1, Table 5). The crude total of emphysema scores averaged 0.77 and 1.36 for those without and with asbestosis diagnosis, respectively-

The general linear models showed significant associations between the dependent variables (the emphysema total score and the individual emphysema subtypes) and the independent variables (Table 4). The coefficient of determination was low in all models $\left(r^{2}=0.04-0.11\right)$.

There was a significant positive correlation between the emphysema and fibrosis scores $\left(r^{2}=0.10, p=0.014\right)$, but the coefficient of determination was low $\left(r^{2}=0.009\right)$.

Pack years were a highly significant predictor of the total score and all emphysema subtypes $(p<0.001$ in all models). Asbestosis was also a significant predictor of the total score $(p=0.041)$, and centrilobular $(p=0.040)$ and paraseptal emphysema $(p=0.018)$. Age and exposure years showed a borderline significance at most.

Table 4. Relation between subtypes of emphysema and the independent variables: Insulators are used as a reference group

\begin{tabular}{|c|c|c|c|c|c|c|c|c|c|c|}
\hline \multirow[b]{3}{*}{ Independent variables } & \multicolumn{10}{|c|}{ Dependent variables } \\
\hline & \multicolumn{2}{|c|}{ Centrilobular } & \multicolumn{2}{|c|}{ Paraseptal } & \multicolumn{2}{|c|}{ Panlobular } & \multicolumn{2}{|c|}{ Bullae } & \multicolumn{2}{|c|}{ Sum score } \\
\hline & est. & $p$ & est. & $p$ & est. & $p$ & est. & $p$ & est. & $p$ \\
\hline Occupational group & & 0.298 & & 0.047 & & 0.025 & & 0.295 & & 0.081 \\
\hline Engineers & -0.21 & 0.179 & -0.28 & 0.024 & -0.18 & 0.17 & -0.17 & 0.105 & -0.81 & 0.067 \\
\hline Electricians & -0.35 & 0.016 & -0.36 & 0.002 & -0.34 & 0.008 & -0.18 & 0.071 & -1.19 & 0.005 \\
\hline Carpenters & -0.24 & 0.064 & -0.25 & 0.014 & -0.33 & 0.003 & -0.11 & 0.208 & -0.91 & 0.014 \\
\hline Plumbers & -0.26 & 0.056 & -0.33 & 0.003 & -0.33 & 0.005 & -0.21 & 0.028 & -1.09 & 0.006 \\
\hline (0-level) Insulators & 0 & .. & 0 & .. & 0 & .. & 0 & .. & 0 & .. \\
\hline Others & -0.24 & 0.053 & -0.25 & 0.01 & -0.22 & 0.031 & -0.15 & 0.074 & -0.83 & 0.017 \\
\hline Age & +0.007 & 0.007 & - & - & +0.006 & 0.094 & - & - & +0.02 & 0.134 \\
\hline Smoking (pack years) & +0.012 & 0.0001 & +0.008 & 0.0001 & +0.005 & 0.001 & +0.004 & 0.001 & +0.03 & 0.0001 \\
\hline Exposure duration & - & - & - & - & - & - & +0.002 & 0.237 & - & - \\
\hline Asbestosis & +0.14 & 0.04 & +0.13 & 0.018 & - & - & +0.07 & 0.136 & +0.41 & 0.041 \\
\hline$r^{2}$ & & 0.11 & & 0.09 & & 0.05 & & 0.04 & & 0.1 \\
\hline
\end{tabular}

est.: Estimate of the score in question, ... : Reference group (0-level), p-value does not apply. -: Variable not included in the model, non-significant in preliminary models 
Table 5. Distribution of the HRCT emphysema total score*) among the occupational groups

\begin{tabular}{lcccccc}
\hline & \multicolumn{5}{c}{ Occupational group } \\
\cline { 2 - 6 } & Engineers & Electricians & Carpenters & Plumbers & Insulators & Others \\
\hline Emphysema total score & $\%$ & $\%$ & $\%$ & $\%$ & $\%$ & $\%$ \\
0 & 60 & 76 & 69 & 70 & 56 & 63 \\
1 & 18 & 14 & 15 & 19 & 14 & 18 \\
2 & 10 & 4 & 5 & 5 & 6 & 7 \\
$3-4$ & 10 & 6 & 6 & 3 & 6 & 7 \\
$5-10$ & 3 & 0 & 0 & 0 & 19 & 3 \\
$11-20$ & 0 & 0 & 2 & 0 & 0 & 2 \\
\hline
\end{tabular}

The scores are averages for 3 readers: 0 meaning $<0.5,1$ meaning $\geq 0.5$ and $<1.5$, etc.

Insulator worker had a higher total score on average (mean=1.36, $\mathrm{SE}=0.20)$ that the other groups (mean $=0.77$, $\mathrm{SE}=0.08)$. The occupational groups differed significantly from each other considering the total score $(p=0.017)$, and paraseptal $(p=0.010)$ and panlobular $(p=0.031)$ emphysema.

\section{Discussion}

In our material, emphysema was most common when workers had asbestosis or were heavily exposed to asbestos.

As expected, smoking was the strongest predictor of emphysema in our study. According to the literature, smoking is associated mainly with centrilobular emphysema ${ }^{9)}$. In our material this association was not so clear; smoking was associated with all emphysema subtypes. Also, patients with diagnosed asbestosis had a significantly higher emphysema total score than those without the disease, but there was an excess of emphysema in workers with heavy asbestos-exposure (insulators), which was not explained by the abovementioned factors or advancing age.

Our subjects were a sample of Finnish construction workers already diagnosed with an asbestos-related disease of the lungs or pleura. We found signs of emphysema in one third of our subjects, as could be expected, since the majority had a smoking history of over 20 pack years. This was due to smoking being one of the inclusion criteria for the original study ${ }^{14)}$ aiming to screen for lung cancer in asbestos exposed workers. The subjects were adjusted for smoking in our general linear models by adding pack years as an independent variable. Thus, other possible causes of emphysema could be assessed in the models.

High tube currents were used in imaging in order to achieve optimal image quality. This was considered essential for imaging small and slender changes in lungs that had been distorted by asbestos-related disease.

The emphysema total score was considered reproducible and reliable. Agreement was high and all subtypes of emphysema were scored consistently by each reader. All variables were considered essential to the score since deleting individual variables did not improve the reliability of the method ${ }^{15)}$.

The prevalence of emphysema in this study was somewhat higher than in some earlier studies. Oksa et $a l .{ }^{16)}$ reported 5 out of 21 asbestos sprayers (24\%) with signs of emphysema in HRCT. Bégin et al. ${ }^{1)}$ studied an emphysema index in 207 workers exposed to mineral dusts. The findings were scored from 0 to 4 based on the presence, type and extent of emphysema in 6 lung zones and then added together to yield the index. The method was regarded as easy to use and 2 out of 3 readers agreed in $63 \%$ of the cases considering emphysema $(\kappa=0.44$ for the entire index). The average score was $0.56(\mathrm{SE}=0.09)$ among patients with asbestosis and $0.21(\mathrm{SE}=0.4)$ among those without the disease. Jarad et al. ${ }^{7)}$ introduced a method analogous to the ILO classification of chest radiographs [scale: 0/- (0) to 3/4 (11) in 6 lung zones] using 24 HRCT slices. Agreement was higher in HRCT than in chest radiography ( $92 \%$ vs. $78 \%$ respectively). All subjects (60 asbestos workers) had some signs of emphysema; the median score being 18/66. These findings are similar to ours, but the prevalence of emphysema in these studies is greater. The two latter methods seem rather lengthy, and the radiation dose in the work of Jarad et al. ${ }^{7)}$ is considerable.

The general linear models confirmed the significant association of smoking with the severity of emphysema. The emphysema scores were highest among insulator workers, who have the heaviest exposure to asbestos. Even though differences between occupational groups are partly caused by individual variation, it seems that asbestos-exposure may play a significant role in causing emphysema.

In earlier studies, emphysema has been associated especially with silicosis and coal workers' pneumoconiosis ${ }^{1-3)}$. Our data indicated a significant 
association between heavy asbestos-exposure and asbestosis with emphysema. The possible (and probable) exposure to silica or other dusts was not possible to define in this study.

There are possible confounding factors that must be kept in mind. The fibrosis in asbestosis causes shrinking and scarring of the lung, which may result in cicatricial emphysema. This might explain the slight, but significant correlation between the emphysema and fibrosis scores. Emphysema is also associated with chronic bronchitis caused by smoking. This may result in a "dirty lung" in chest radiography and be mistaken for fibrosis. Chronic bronchitis and emphysema also impair lung function, which may also lead to a false diagnosis of asbestosis, both in lung function tests and in radiological examinations.

In conclusion, we found an excess of emphysema in workers with heavy exposure to asbestos and in patients with asbestosis, but the causative role of asbestos in emphysema requires further investigation.

Acknowledgments: The authors wish to thank Mr. Kristian Taskinen for his contribution to the statistical modeling of the data, and Dr. Hannu Lehtola for the patient interviews. We wish to thank Dr. Antti Tossavainen for his expertise in occupational hygiene and epidemiology.

\section{References}

1) R Bégin, R Filion and G Ostiguy: Emphysema in Silicaand Asbestos-Exposed Workers Seeking Compensation. A CT Scan Study. Chest 108, 647-655 (1995)

2) Weill H, Jones RN, Parkes WR. Silicosis and related diseases. In: Parkes WR, Ed. Occupational Lung Disorders, $3^{\text {rd }}$ Edition. Oxford: ButterworthHeinemann, 1994: 285-339.

3) Parkes WR. Pneumociniosis associated with coal and other carbonaceous materials. In: Parkes WR, Ed. Occupational Lung Disorders, $3^{\text {rd }}$ Edition. Oxford: Butterworth-Heinemann, 1994: 340-410.

4) Browne K. Asbestos-related disorders. In: Parkes WR, Ed. Occupational Lung Disorders, $3^{\text {rd }}$ Edition. Oxford: Butterworth-Heinemann, 1994: 411-504.
5) C Sanders: The radiographic diagnosis of emphysema. Radiol Clin North Am 29, 1019-1030 (1991)

6) WR Webb: High-resolution computed tomography of obstructive lung disease. Radiol Clin North Am 32, 745-757 (1994)

7) NA Jarad, P Wilkinson, MC Pearson and RM Rudd: A new high resolution computed tomography scoring system for pulmonary fibrosis, pleural disease, and emphysema in patients with asbestos related disease. Br J Ind Med 49, 73-84 (1992)

8) Webb WR, Müller NL, Naidich DP. High-Resolution CT of the Lung, $2^{\text {nd }}$ Edition. Philadelphia: LippincottRaven Publishers, 1996: 85-88.

9) Parkes WR. Chronic bronchitis, airflow obstruction and emphysema. In: Parkes WR, Ed. Occupational Lung Disorders, $3^{\text {rd }}$ Edition. Oxford: ButterworthHeinemann, 1994: 222-237.

10) K Koskinen, J-P Rinne, A Zitting, A Tossavainen, J Kivekäs, K Reijula, P Roto and MS Huuskonen: Screening for Asbestos-Induced Diseases in Finland. Am J Ind Med 30, 241-251 (1996)

11) K Koskinen, A Zitting, A Tossavainen, JP Rinne, $P$ Roto, J Kivekäs, K Reijula and MS Huuskonen: Radiographic abnormalities among Finnish construction, shipyard and asbestos industry workers. Scand J Work Environ Health 24, 109-117 (1998)

12) O Huuskonen, L Kivisaari, A Zitting, K Taskinen and T Vehmas: High-resolution computed tomography classification of lung fibrosis for patients with asbestosrelated disease. Scand J Work Environ Health 27, 106112 (2001)

13) JM Bland and DG Altman: Cronbach's alpha. BMJ 314, 572 (1997)

14) M Tiitola, L Kivisaari, MS Huuskonen, K Mattson, $H$ Koskinen, H Lehtola, A Zitting and T Vehmas: Computed tomography screening for lung cancer in asbestos-exposed workers. Lung Cancer 35, 17-22 (2002)

15) Kinnear PR, Gray CD. SPSS for Windows Made Simple. Release 10. East Sussex: Psychology Press, 2000.

16) P Oksa, H Suoranta, H Koskinen, A Zitting and $\mathrm{H}$ Nordman: High-resolution computed tomography in the early detection of asbestosis. Int Arch Occup Environ Health 65, 299-304 (1994) 